\title{
O IMPACTO DO EXERCÍCIO DE ATIVIDADE REMUNERADA NA MATURIDADE PARA A ESCOLHA PROFISSIONAL
}

\author{
Adrielly Silva ${ }^{1}$ \\ Eduarda Dornelas ${ }^{1}$ \\ Fernanda Mian de Lima $^{1}$ \\ Jessica Aguiar Mota ${ }^{1}$ \\ Jhonantan Novaes de Souza ${ }^{1}$ \\ Henrique César Saldanha Rocha ${ }^{2}$
}

\section{RESUMO}

INTRODUÇÃO: A escolha da profissão geralmente acontece na adolescência, uma fase marcada por profundas mudanças, e neste momento complexo será tomada uma das decisões mais importantes da sua vida. O trabalho do profissional da Psicologia torna-se de suma importância para que essa escolha seja assertiva. OBJETIVO: Comparar o nível de maturidade para escolha profissional considerando o grupo que exerce alguma atividade remunerada em relação ao grupo que não exerce. METODOLOGIA: O presente estudo foi desenvolvido através de uma pesquisa qualitativa-quantitativa, transversal e descritiva, na qual foi utilizada a Escala de Maturidade para a Escolha Profissional (EMEP) juntamente com um questionário sócio, econômico demográfico. O EMEP é composto por cinco sub-escalas: determinação, responsabilidade, independência, autoconhecimento e conhecimento da realidade. As atividades foram desenvolvidas em dois encontros, no primeiro os estudantes foram esclarecidos sobre o projeto e após as orientações sobre o instrumento utilizado, o mesmo foi aplicado; no segundo encontro, cada participante recebeu uma devolutiva individual de acordo os resultados obtidos. A amostra foi composta por 437 adolescentes, com idade entre 16 e 19 anos, matriculados no terceiro ano do ensino médio, de ambos sexos, distribuídos em 9 escolas públicas e 1 privada, nas cidades de Abadia dos Dourados, Coromandel, Douradoquara e Romaria. RESULTADOS: Dos participantes, 259 (59\%) não

\footnotetext{
${ }^{1}$ Acadêmicos do curso de Psicologia da Faculdade Cidade de Coromandel - FCC.

${ }^{2}$ Graduado em Psicologia pela Universidade de Uberaba e Especialista em Saúde Coletiva pela Universidade Federal do Triângulo Mineiro - UFTM.
} 

exerciam nenhum tipo de atividade remunerada, e 178(41\%) exerciam algum tipo de atividade remunerada. Na subcategoria Determinação, exceto na faixa etária de 18 anos, os alunos que exercem alguma atividade remunerada apresentaram níveis de maturidade mais elevados em relação aos alunos que não exercem atividade remunerada. $\mathrm{Na}$ subcategoria Responsabilidade, somente na faixa etária de 16 anos, os alunos que exercem atividade remunerada apresentaram um nível de maturidade mais elevado em relação aos alunos que não exercem atividade remunerada. Nassub-categorias Independência e autoconhecimento, em todas as idades pesquisadas, os alunos que exerciam algum tipo de atividade remunerada apresentaram níveis de maturidade mais elevados em relação aos alunos que não exerciam atividade remunerada. Na subcategoria Conhecimento da Realidade, exceto na idade de 19 anos, os alunos que exerciam atividade remunerada apresentaram níveis de maturidade mais elevados. CONSIDERAÇÕES FINAIS: Os dados apontam que os estudantes que exercem alguma atividade remunerada tendem a apresentar um nível de maturidade mais elevado para a escolha profissional. A experiência de exercer uma atividade remunerada já coloca o jovem em contato com o mercado de trabalho, o que desenvolve algumas habilidades, e pode ser um grande indicador para a escolha profissional.

Palavras Chave: Adolescente; Orientação Profissional; Escolha da Profissão; Trabalho 